\title{
O LUGAR DA FILOSOFIA NA CONTEMPORANEIDADE
}

\author{
Claudecir Dos Santos ${ }^{1}$ \\ Universidade Federal da Fronteira Sul (UFFS) \\ (D) https://orcid.org/0000-0003-3304-757X \\ Odair Neitzel $^{2}$ \\ Universidade Federal da Fronteira Sul (UFFS) \\ Universidade de Passo Fundo (UPF) \\ https://orcid.org/0000-0001-8121-1149
}

\section{RESUMO:}

A distinta experiência de ocupar e ser um lugar na história da humanidade pode simbolizar, ao mesmo tempo, força e fraqueza de quem vivencia esse fenômeno. Contudo, quem consegue esse feito, conquista a condição de reencontrar-se em diferentes tempos históricos, rever sua essência e avaliar sua existência. Este é o caso da filosofia. Ao longo da história, ela tanto ocupou um lugar, como também foi esse lugar. E hoje, qual é o lugar da filosofia? É em torno dessa questão que emergem as principais reflexões que dão vida a esse trabalho. Fundamentando-se em conceitos e ideias dos filósofos Pierre Hadot, Walter Benjamin e Giorgio Agamben, o presente artigo propõe um debate sobre o lugar da filosofia na contemporaneidade, tentando entender se esse lugar realmente existe, e quem nele pode morar.

PALAVRAS-CHAVE: Filosofia; Lugar; Contemporaneidade.

\section{THE PLACE OF PHILOSOPHY IN CONTEMPORARY}

\footnotetext{
ABSTRACT:

The distinctive experience of taking and being a place in the history of mankind can symbolize at the same time, strength and weakness of those who experience this phenomenon. However, who can this feat, winning the

${ }^{1}$ Doutor em Filosofia. Professor da Universidade Federal da Fronteira Sul (UFFS), Santa Catarina-Brasil. E-mail: claudecir.santos@uffs.edu.br

${ }^{2}$ Doutorando em Educação pela Universidade de Passo Fundo ( UPF), Rio Grande do sul Brasil. Professor da Universidade Federal da Fronteira Sul (UFFS), Santa Catarina - Brasil. E-mail: odair.neitzel@uffs.edu.br
} 
condition to find itself in different historical times, review its essence and evaluate their existence. This is the case of philosophy. Throughout history, both she occupied a place, as was this place. And today, what is the place of philosophy? It is around this question emerging from the main reflections that give life to this work. Basing on concepts and ideas of the philosophers Pierre Hadot, Walter Benjamin and Giorgio Agamben, this article proposes a debate on the place of philosophy in contemporary times, trying to understand if this place actually exists, and who can live in it.

KEYWORDS: Philosophy; Place; Contemporaneity.

\section{Introdução}

Existe um lugar para a filosofia na contemporaneidade? O desejo em encontrar uma resposta positiva a essa pergunta, somado à necessidade de problematizá-la, tem nos levado a refletir sobre esse tema. Quando desconfiamos que sim, existe um lugar para a filosofia na contemporaneidade, logo nos perguntamos: que lugar é esse e quem pode nele viver? A respeito dessa pergunta, o que descobrimos e queremos compartilhar é que, somente quando lançamos olhares mais atentos a esse lugar é que conseguimos enxergar quem pode nele viver.

É importante esclarecer que quando nos referimos ao lugar, falamos de tudo aquilo ao qual um ser pode encontrar abrigo. Assim, poderíamos dizer: a filosofia é o lugar onde a sabedoria é vivenciada, onde vivem pessoas despertas etc. O lugar do qual falamos é o que expressa mais a situação ocupada por alguém do que o espaço que um corpo habita. ${ }^{3}$

Atualmente existem muitas teorias, conceitos, ideias e opiniões com conteúdos filosóficos que se tornaram lugares-comuns. Temos a impressão que entre esses lugares-comuns, a filosofia propriamente dita, em vez de ser uma anfitriã acolhedora, cada vez mais, é enxergada como uma senhora estranha e chata. Diante desse cenário nos propomos a problematizar algumas questões que cercam essas impressões.

Sabemos que o enfrentamento dessa realidade não é simples, por isso buscamos auxilio nas reflexões de pensadores que ao longo de suas produções filosóficas, direta e indiretamente, tiveram e continuam tendo posicionamentos que caminham em direção as preocupações aqui expostas. Para esse momento, buscamos auxílio em algumas contribuições dos filósofos Pierre Hadot, Walter Benjamin e Giorgio Agamben.

\footnotetext{
${ }^{3}$ De acordo com o Dicionário de Filosofia, numa referência a Descartes "o lugar e o espaço são diferentes: o lugar nos marca mais expressamente a situação que a grandeza ou a figura; ao contrário, pensamos mais nesta quando falamos de espaço". Essa diferenciação é importante para esse artigo, ela ajuda a esclarecer seus propósitos ao se se referir ao lugar, ou seja, seu desejo é enfatizar mais a situação do que a grandeza ou a figura (JAPIASSÚ e MARCNDES, 2008, p. 173).
} 
Assim sendo, inicialmente, são as percepções de Pierre Hadot sobre a filosofia como uma forma de vida que direcionam e fundamentam as reflexões a que o artigo se propõe. Conforme veremos, Hadot diferencia filosofia de discursos filosóficos para esclarecer como, ao longo da história, a filosofia foi perdendo a condição de ser uma forma de vida.

Em seguida, para resgatar e problematizar a importância de um olhar filosófico às experiências contemporâneas, o artigo faz referência ao conceito de experiência coletiva (Erfahrung) do filósofo alemão Walter Benjamin. O lugar da filosofia, como veremos, passa pela vivência de experiências coletivas.

$\mathrm{Na}$ terceira seção, partindo das considerações benjaminianas, o artigo apresenta algumas observações sobre a formação filosófica e a constituição de sujeitos na contemporaneidade. A fundamentação desse tema está centrada nas teses do filósofo italiano Giorgio Agamben sobre o que é o contemporâneo?, e o que significa viver na contemporaneidade. É nesse cenário que acontece a formação filosófica que poderá ou não contribuir para a constituição de sujeitos, daí o desejo e necessidade em melhor compreendê-lo.

É em torno desses assuntos que o presente artigo está construído. Como conclusões prévias, podemos dizer que sim: existe um lugar para a filosofia na contemporaneidade, mas esse lugar não se oferece a ela gratuitamente. É nesse contexto que as experiências coletivas e as experiências que possibilitam seres humanos constituírem-se como sujeitos de seu tempo, passam a ser importantes à filosofia. Em síntese, é este o enfoque do presente artigo.

\section{Pierre Hadot e a filosofia como forma de vida}

"Cambiar la vida. Cambiar, por lo menos una vida. Pocos libros tienen este efecto. [...] You changed my life" (HADOT, 2009, p. 9). Eis aí uma afirmação importante à filosofia. A nosso ver, além de importante, verdadeira. Essas duas palavras, aliás, se a filosofia voltasse à antiguidade, se transformariam em um pleonasmo. Infelizmente, não podemos dizer que isso se aplica inteiramente a contemporaneidade. Agora, à filosofia, até pode se atribuir importância e verdade, mas não significa que com isso ela provocará mudanças na vida das pessoas.

A afirmação inicial, porém, deixa em aberto uma possibilidade. Ou seja, quando ela expressa que poucos livros têm o efeito de mudar uma vida, o "poucos", representa alguma coisa. Assim, podemos dizer que, pelo menos, alguns livros ainda conseguem esse efeito. E quais seriam esses livros? Ou, melhor dizendo, qual seria o livro que se tornou objeto da afirmação em questão?

Trata-se do livro: Qué es la filosofía antigua, de Pierre Haddot, professor emérito do Collège de France, onde foi catedrático da disciplina 
de História do pensamento helenístico e romano. Quem fez a afirmação foi um jovem historiador norte-americano após ler a obra de Hadot. A conclusão do jovem foi essa: você mudou minha vida.

Quem nos conta essa experiência é Jeannie Carlier, na introdução de outro brilhante livro de Pierre Hadot, La filosofía como forma de vida: conversaciones con Jeannie Carlier y Arnold I. Davidson. Em forma de entrevista, Carlier e Davidson dialogam com Pierre Hadot sobre temas ligados a filosofia antiga, especialidade de Hadot, passando pela Idade Média, até adentrar na modernidade. No decorrer do diálogo, Hadot vai mostrando como o discurso filosófico e a filosofia como uma forma de vida, se estabeleceram ao longo da história.

Discurso filosófico e filosofia como forma de vida, portanto, são coisas diferentes. $\mathrm{Na}$ interpretação de Hadot, na antiguidade, a filosofia como forma de vida era mais presente na vida dos filósofos do que o discurso filosófico. Isso se deve ao fato de que, "los filósofos que fundaron escuelas quisieron, al hacerlo, promoner modos de vida. Esto quiere decir que, en la formación del pensamiento de Platón o de Aristóteles o de Epicuro, el factor principal me parece que es la representación de cierto modo de vida" (HADOT, 2009, p. 159).

Hadot faz um resgate das principais escolas filosóficas da antiguidade, pelo menos daquelas que temos conhecimento, para mostrar que, embora expressem pensamentos contrários, elas defendem os princípios que apresentam e desejam que as pessoas os sigam, ou seja, a razão delas existirem é a possibilidade de fazer com que as pessoas vivam segundos seus princípios.

Essa postura das escolas filosóficas da antiguidade caracterizou a filosofia antiga, entretanto, com o decorrer dos séculos, ela foi sendo substituída por outras formas de se pensar e fazer filosofia. Por exemplo, alguns traços conspícuos da modernidade, que se intensificaram na contemporaneidade, demonstram que fazer da filosofia uma forma de vida como faziam os antigos está cada vez mais difícil. Hadot nos ajuda a compreender melhor essa situação ao afirmar que, "hay que reconocer que los filósofos antiguos se preocuparon intensamente por los demás" (HADOT, 1999, p. 164).

Podemos dizer que essa postura, pelo menos da forma que acontecia na antiguidade, é hoje uma raridade. O exemplo de Sócrates é o que talvez melhor represente esse preocupar-se com os demais, ou seja: "Sócrates se presenta como aquel que há recibido la misión de ocuparse de los demás, de hacerles tomar la decisión de preocuparse por sí mismos ((HADOT, 1999, p. 164).

Preocupar-se com os demais, porém, não era uma ação que acontecia separada do conhece-te a ti mesmo. Sócrates é exemplar nesse caso, porque perseguiu uma forma de vida que o acompanhou até a sua morte. A morte de Sócrates, aliás, representa, exatamente, o que seria a verdadeira experiência 
de se preocupar com o outro, sem deixar de cuidar-se de si. Assim, por mais paradoxal que isso possa parecer, o caminho que escolheu percorrer, ao mesmo tempo em que levou Sócrates à morte, levou-o ao cuidado de si e dos outros.

Era esse jeito de viver a filosofia que lhe dava a condição de ser apontada como uma forma de vida. Aos poucos, conforme nos esclarece Hadot, essa filosofia foi perdendo lugar para discursos filosóficos encarregados de responder questões mais de ordem teórica do que questões relacionadas ao cotidiano. Um momento crucial para essa mudança aconteceu com o advento do cristianismo, na transição entre o período antigo para o período medieval.

$\mathrm{Na}$ concepção de Hadot, essa mudança representou um retrocesso à filosofia. A razão desse retrocesso é obvia: a filosofia deixou de possibilitar às pessoas a condição de se encontrarem em suas buscas existenciais para servir como instrumento para encontrar respostas em "coisas" distantes. Sobre isso, Hadot faz a seguinte observação: "creo que lo que jugó un gran papel en esto retroceso fue el trinfo del cristianismo" (HADOT, 2009, p. 172). No entender de Hadot, desde o final da antiguidade, para contrapor-se as filosofias pagãs, a teologia, que depois predominaria na Idade Média, transformou a filosofia em discursos filosóficos para explicar problemas teológicos. É ai que se concentra o retrocesso do qual fala Hadot.

Diante dessa realidade, a escolástica medieval ganhou as universidades da época e, com ela, a filosofia passou a ser instrumento para resolver problemas que os dogmas religiosos traziam à baila. Assim, a servidão da filosofia contribuiu para que ela não alcançasse a possibilidade de se tornar uma forma de vida.

Esta experiência pela qual passou a filosofia ajuda-nos a entender a diferença em ser um lugar e ocupar um lugar. Na antiguidade a filosofia era ou estava próxima da primeira condição, com o seu esvaziamento no período medieval, ela rumou para a segunda condição. Hadot destaca que a experiência filosófica medieval foi tão marcante a filosofia, a ponto de ultrapassar os séculos correspondes a esse período. Dessa forma, argumenta Hadot,

\footnotetext{
Por una parte, la escolástica se perpetuó al menos hasta el final del siglo XVIII y, por otra parte, a partir del momento en que la filosofía conquistó su autonomía, se encontró, al menos hasta el siglo XVIII e incluso después, en una civilización oficialmente cristiana, en la que el modo de vida era cristiano: la filosofía no podía proponer otro modo de vida que el que estaba ligado a la teología cristiana. Así pues siguió siendo una disciplina sobre todo teórica (HADOT, 1999, p. 173).
}

De acordo com as afirmações do filósofo, a partir da modernidade, a filosofia seguiu essa mesma pegada. Quando observamos os rastros dessas pegadas, não recuperamos apenas a trajetória da filosofia, além disso, 
ampliamos as nossas compreensões acerca do lugar da filosofia em cada momento da nossa história. No nosso caso, esse momento é a contemporaneidade.

É impossível descrever em um artigo de 15 páginas o longo caminho percorrido pela filosofia, por conta disso, seguindo os apontamentos dos autores que estão nos auxiliando nesse trabalho, nossa intenção é olhar para os lugares da filosofia, mas não julgá-los, absolvê-los ou condená-los. Até mesmo Pierre Hadot que tem propriedade para falar de um período da filosofia, a antiguidade, não segue esse caminho. No diálogo com seus interlocutores, na obra Lá filosofía como una forma de vida, por exemplo, mesmo quando aponta o dedo para a história da filosofia, descrevendo as consequências dela perder espaço para os discursos filosóficos, ele não se comporta como um juiz, muito menos como um pessimista em relação ao futuro da filosofia.

Em nosso entendimento, ao voltar-se a história, a intenção de Hadot é mostrar como a filosofia foi, passou a ser, é, e ainda poderá vir a ser. Preocupamo-nos com essa última possibilidade. Em função disso, defendemos que o lugar da filosofia precisa ser preparado, mas não só com e através de discursos filosóficos. Esse lugar precisa ser pensado e vivenciado a partir de uma mudança em nossas experiências. Como isso é possível? Revendo nossas experiências coletivas. Quem nos ajuda a melhor entender tudo isso é o filósofo alemão Walter Benjamin.

\section{A importância de um olhar filosófico às experiências contemporâneas: por um resgate da experiência coletiva}

De acordo com Walter Benjamin, a partir da modernidade, passamos a viver em um contexto de pobreza de experiências, ou experiência empobrecidas. Isso não significa dizer que antes da modernidade somente existiam experiências coletivas libertadoras, significa dizer que a modernidade, em razão, em grande medida, da concepção de progresso e desenvolvimento emergentes, intensificou essa pobreza.

A experiência coletiva (Erfahrung) é entendida por Benjamin como uma experiência aberta que se aproxima mais da alegoria, por suscitar muitas leituras e muitos sentidos sobre ela, do que do símbolo que possibilitaria um significado unilateral. Tal experiência poderá transformarse numa busca para com a emancipação humana, isso porque, graças a ela, o passado, o presente e o futuro poderão ser movimentados através da rememoração de tais experiências. Ao contrário, a experiência individualizada (Erlebnis) é a própria expressão de um mundo fragmentado. Reproduzindo-se como uma sequência de vivências individualizadas, esse tipo de experiência produz um ser humano individualista que, consequentemente, passa a acreditar na crença de uma história linear, ou seja, acredita que as coisas são assim mesmo e que cada um deve pensar 
somente em si, por conta dessa mentalidade, quem a conserva, não consegue enxergar outras possibilidades.

Além disso, esse novo conceito de experiência, caracterizado pelas vivências individuais, causa uma despersonalização generalizada que leva as pessoas a se apropriarem e valorizarem objetos, a viverem sob a égide da materialidade. "Despossuído do sentido da vida, o indivíduo tenta, desesperadamente, deixar a marca de sua possessão nos objetos pessoais" (GAGNEBIN, 1994, p.68), essa é a opção que lhe resta, já que não é mais ele mesmo. Em outras palavras, na medida em que se perde o sentido do coletivo, perde-se também a personalidade individual e, daí, o poder dos dominantes, ou seja, a existência da condição do domínio sobre as massas.

Quanto às possibilidades de interiorização das experiências, Benjamin afirma que elas são transmitidas de modo benevolente ou ameaçador, conforme o ser humano vai se desenvolvendo. Observando uma realidade pré-moderna Benjamin diz que algumas expressões comumente usadas, como: "ele é ainda muito jovem, mas em breve poderá compreender", ou, "um dia ainda compreenderá" revelam, segundo Benjamin, que "sabia-se exatamente o significado da experiência" (BENJAMIN, 1994a, p.114). Nas análises do autor, a compreensão do significado da experiência era possível porque ela sempre fora comunicada aos jovens e essa comunicação acontecia "de forma concisa e com a autoridade da velhice, em provérbios; de forma prolixa com a sua loquacidade, em histórias; muitas vezes como narrativas de países longínquos, diante da lareira, contadas a pais e netos" (BENJAMIN, 1994a, p.114). Aos poucos, porém, ela foi empobrecendo e, diante desse empobrecimento, Benjamin pergunta: "que foi feito de tudo isso? Quem encontra ainda pessoas que saibam contar histórias como elas devem ser contadas? Quem tentará, sequer, lidar com a juventude invocando sua experiência?" (BENJAMIN, 1994a, p.114).

Os questionamentos benjaminianos nos levam a pensar sobre o lugar da filosofia e as condições para a formação filosófica na contemporaneidade. Ou seja, o que estamos defendendo nesse artigo é a necessidade de um olhar às experiências contemporâneas que seja capaz de enxergar nelas as condições ou não para a constituição de sujeitos. Se essas experiências acontecerem entrelaçando pensamento, história e atualidade, então, elas terão o status de uma experiência coletiva, conforme descreveu Benjamin, pois terão conquistado a possibilidade de serem transmitidas, é imbricado nessa transmissão que a constituição do sujeito ganha vida.

Diante disso, somos levados a acreditar que o lugar da filosofia na contemporaneidade é aquele onde as experiências coletivas acontecem e conseguem ser transmitidas. O envolvimento ativo e crítico de cada um e de cada uma na vivência e transmissão de uma experiência expressa o que seria uma formação filosófica capaz de fazer da filosofia um lugar para se morar. Mas isso tudo deve acontecer em conjunto. Em outras palavras, não cabe à 
filosofia analisar experiências para explicá-las através de discursos filosóficos, é a própria filosofia que precisa ser uma experiência coletiva.

Sobre isso, é importante fazer dois esclarecimentos. O primeiro se refere as condições para a execução dessa tarefa, é preciso entender que ela não deve ser encarada de qualquer forma, a correr o risco de baratear a filosofia, já existem muitos fazendo isso. Assim, fazer da filosofia uma experiência coletiva exige conhecê-la a partir dos lugares onde ela foi e esteve. O segundo esclarecimento é sobre Walter Benjamin, ou seja, ele não apresentou o conceito de experiência coletiva com a intenção de que tal conceito se tornasse um novo instrumento para a filosofia, as intenções do filósofo eram maiores, suas preocupações eram com a humanidade. Aproveitando-se desse raciocínio, é oportuno dizer que, assim como Benjamin, nós também não nos referimos a esse conceito como aquilo que resta à filosofia. Mas, seria também incoerente de nossa parte não defender a experiência coletiva como uma possibilidade viável e enriquecedora à filosofia contemporânea.

Em síntese, diante dessas rápidas contribuições de Pierre Hadot e Walter Benjamin, podemos dizer que: se quisermos contribuir para que a filosofia tenha e seja um lugar na contemporaneidade, então, o olhar filosófico às experiências contemporâneas deve guiar e ser guiado por experiências coletivas. No nosso entender, uma formação filosófica que perceba essa realidade será capaz de contribuir de forma significativa para a constituição de sujeitos na contemporaneidade. Sobre essa tarefa e sobre o significado de ser contemporâneo e estar na contemporaneidade, recorremos às contribuições do filósofo italiano Giorgio Agamben.

\section{A formação filosófica e a constituição de sujeitos na contemporaneidade}

Ter a capacidade de perceber no escuro do presente a luz que procura nos alcançar e não pode fazê-lo, isso significa ser contemporâneo. Essa é a tese defendida por Giorgio Agamben sobre o que significa ser contemporâneo e viver a contemporaneidade. Nesse sentido, ser sujeito da contemporaneidade significa apropriar-se dela, mas, para Agamben, o sujeito, aquele que ocupa o tempo, "é resultado da relação entre os seres viventes (ou substâncias) e os dispositivos ${ }^{4}$ em que estes são capturados" (AGAMBEM, 2009, p.40-1). Por isso, para que esse sujeito possa ser

\footnotetext{
${ }^{4}$ Partindo de uma concepção foucaultiana, Agamben chama, literalmente, de dispositivo "qualquer coisa que tenha de algum modo capacidade de capturar, orientar, determinar, interceptar, modelar, controlar e assegurar os gestos, as condutas, as opiniões e os discursos dos seres viventes. Não somente, portanto, as prisões, os manicômios, o Panóptico, as escolas, a confissão, as fábricas, as disciplinas, as medidas jurídicas etc., cuja conexão com o poder é num certo sentido evidente, mas também a caneta, a escritura, a literatura, a filosofia, a agricultura, o cigarro, a navegação, os computadores, os telefones celulares e porque não - a própria linguagem, que talvez seja o mais antigo dos dispositivos" (AGAMBEN, 2009, p. 40-1).
} 
contemporâneo e viver a contemporaneidade ele não pode se deixar cegar pelas luzes do tempo que vive. Ser sujeito, portanto, é mais do que ser apenas um ser vivente, para ser sujeito é preciso, em alguma medida, ter uma relação ativa na e sobre as criações dos dispositivos que "guiarão" as vidas dos seres viventes.

O sujeito do qual tratamos é aquele que supera os aprisionamentos e as diferentes formas de escravidão, não se submetendo ingenuamente aos direcionamentos de outros. O sujeito ao qual nos referimos é aquele que consegue dizer que tornar-se sujeito é possível, porque sabe que não existe nenhuma lei, terrena ou divina, que impeça alguém de ser protagonista de sua história, senhor de suas escolhas, dono de sua vida. Com isso, porém, não estamos sinalizando para a existência de um sujeito por natureza. Apenas afirmamos que o sujeito do qual estamos tratamos é aquele que se constrói como tal.

É curioso, no entanto, que as mesmas pessoas que se tornam sujeitos, aquelas que criam os dispositivos que passarão a demarcar suas condutas, devido, talvez, ao aumento das relações humanas, dos humanos com as coisas e delas com os dispositivos que as tornam desejáveis, independente de suas utilidades, não raras vezes, se tornam escravos daquilo que eles próprios criam. Ou seja, para manter o mundo das criações em movimento, os criadores instituem nas criações códigos, senhas, números etc., um verdadeiro labirinto. Nesse ritmo, aos poucos, eles se tornam dependentes das criações e passam a vida procurando alternativas para chegar pelo menos à porta por onde entraram no labirinto.

A contemporaneidade é esse labirinto. Por isso, admite Agamben, "os contemporâneos são raros". Afinal de contas, ser contemporâneo, nas condições descritas pelo filósofo, é ter a condição de enxergar, no presente, as luzes das sobras e as sobras das luzes. Nas palavras de Agamben,

A contemporaneidade é uma singular relação com o próprio tempo, que adere a este e, ao mesmo tempo, dele toma distâncias; mais precisamente, essa é a relação com o tempo que a este adere através de uma dissociação e um anacronismo. Aqueles que coincidem muito plenamente com a época, que em todos os aspectos a esta aderem perfeitamente, não são contemporâneos porque, exatamente por isso, não conseguem vê-la, não podem manter fixo o olhar sobre ela (AGAMBEN, 2009, p. 59).

Se as teses de Agamben estiverem corretas, também será correta a afirmação de que a relação, ora de intimidade, ora de distanciamento do sujeito para com o tempo que vive, antes de ser um problema, é uma possibilidade para ser contemporâneo e viver a contemporaneidade. Mas é preciso que a tomada de consciência dos seres humanos acerca do tempo que estão vivendo seja acompanhada da capacidade de distanciamento do 
tempo presente, isso os permitirá uma não adesão e interiorização completa, ingênua, portanto, da realidade vivida.

De acordo com o pensamento de Agamben, a aproximação e o distanciamento do tempo é uma chance a mais que os seres humanos contemporâneos têm para viver de fato a contemporaneidade. Entretanto, os sujeitos continuam sendo raros. Uma das razões para isso talvez esteja no fato da contemporaneidade criar "tipos", "caricaturas" de pessoas que recebem o título de sujeitos.

O problema em privilegiar os "tipos" e "caricaturas" de sujeitos está no perigo de esquecer que antes deles existem seres humanos sedentos de saberes, afetividade, amor e humanidade. São esses seres que podem se tornar sujeitos de suas vidas. E realmente podem, basta que as condições adequadas para isso sejam criadas. Mas, será possível realizar esse feito na contemporaneidade? Sim, será possível, contudo, é preciso lembrar que são muitas as forças que tentarão impedir. As mesmas forças que se apresentarão como contribuintes de um processo de transformação e evolução poderão ser as mais destruidoras. ${ }^{5}$

Uma tarefa hercúlea como essa não se desenvolve sem que muitas armadilhas sejam deixadas pelo caminho. ${ }^{6}$ Nelas, diversos e muito bem organizados estratagemas surgem com a intenção de fazer com que os sujeitos e não sujeitos se posicionem e tomem partido em relação às novas ondas, tendências, modismos e dispositivos que se apresentam como a nova ordem a ser seguida.

São essas forças que precisam ser claramente identificadas e apontadas como responsáveis, se de fato o são, pelos entraves que os seres viventes encontram para se tornarem sujeitos. Vale lembrar que a própria interpretação dada ao conceito sujeito é um exemplo das confusões que complicam a relação entre ser vivente e as suas condições para se tornar sujeito. Sobre isso, porém, seguimos a interpretação que parte da metafísica clássica, chega à modernidade, dialoga com a teoria do conhecimento, e se aproxima da contraposição entre sujeito transcendental e epistêmico. Em todo esse percurso, ser sujeito sempre implicou em ser alguém que possui atributos, que tem consciência, que conhece. É desse sujeito que falamos.

Mas se estes sujeitos são raros, de quem é a culpa? Noutro sentido, qual é a gênese da submissão letárgica que leva seres humanos a não se tornarem sujeitos de seu tempo? Existem muitas hipóteses em torno dessas questões, infelizmente, não temos tempo e condições para aprofundá-las nesse momento, por isso apenas indicamos que a culpa não recai somente em cima daqueles e daquelas que estão passando pela contemporaneidade,

\footnotetext{
${ }^{5}$ Não é possível indicar/nomear quais são essas forças uma por uma, mas é possível dizer que entre elas estão as que se impõe através do mercado e da lógica do capital que escraviza mentes humanas e faz de pessoas objetos de uso e consumo.

${ }^{6}$ No mesmo sentido da nota anterior. Ou seja, as armadilhas estão entre as forças que escravizam mentes e impedem a emancipação humana.
} 
mas ressaltamos que também não terão nenhum alento aqueles e aquelas que continuarem mergulhados em uma ingenuidade da qual, em parte, são cúmplices.

Apesar dos desafios que essa realidade expressa, continuamos acreditando que ser contemporâneo na contemporaneidade é possível. O que propomos para a efetivação dessa realidade é um olhar às condições de vida que um passante da contemporaneidade vivencia, e as possibilidades que dai decorrem para que ele se torne um sujeito dono de sua vida.

Ao fazer esse exercício, voltamo-nos às instituições que participam ativamente da formação de seres humanos na contemporaneidade. Entre elas, estão as instituições de ensino. São nesses espaços que os saberes são sistematizados, elaborados, defendidos e refutados. Aqui, nos encontramos com as questões que deram início as nossas reflexões, mas agora, em vez de nos perguntarmos se existe um lugar para a filosofia na contemporaneidade? A pergunta que fazemos é: será que formação filosófica vivenciada nessas instituições de ensino está conseguindo enfrentar a contemporaneidade a ponto de fazer dos contemporâneos sujeitos do seu próprio tempo?

Somos defensores da ideia de que há lugar para a filosofia na contemporaneidade, mas não procuremos por ele somente nas instituições de ensino, é possível que aí sejam encontrados mais discursos filosóficos do que uma filosofia com condições de se tornar uma forma de vida, conforme descreve Hadot. Sim, existe um lugar para a filosofia na contemporaneidade e muitos nele podem morar, mas é preciso que saibam que para nele viver é preciso ter coragem de resistir, inteligência para se posicionar e vontade de fazer do ordinário, algo extraordinário.

É para esse fenômeno que os seres humanos da contemporaneidade devem voltar seus olhares se dela pretendem se tornar contemporâneos. Para tanto, é importante e necessário que todos, minimamente, se conheçam. É aqui que inicia a tarefa filosófica contemporânea. Apropriar-se do grande tempo a ponto de não ser engolido pelos instantes e suas superficialidades, eis a experiência a ser construída. A filosofia tem potencial para execução dessa tarefa. Se tal potencialidade for vivenciada, a constituição de sujeitos estará a caminho.

\section{Considerações finais}

As rápidas reflexões apresentadas nesse artigo nos permitem afirmar que ao longo da história ocidental a filosofia foi sendo vivenciada segundo princípios e interesses de escolas filosóficas, correntes de pensamento e teorias detentoras da possibilidade de exteriorizar e legitimar conhecimentos.

Seguindo o pensamento de Hadot, Benjamin e Aganben, podemos dizer que as transformações que a sociedade ocidental vivenciou, da antiguidade à contemporaneidade, interferiu, e muito, no lugar da filosofia no decorrer dos séculos. Foram tantas as modificações que precisaria um 
livro inteiro para descrever que lugar a filosofia ocupou em cada período e o que nele produziu. Como a intenção do trabalho não era essa, valemo-nos das observações apresentadas para lembrar que a filosofia chegou à contemporaneidade, nela tem um lugar, e nele precisa agir. Precisamos atentar com sabedoria e responsabilidade.

Obviamente, seguindo o raciocínio dos atores citados, o "chegar" até aqui, da forma que chegamos, não é motivo somente para aplausos. Isso porque, viemos arrastados por um empobrecimento de experiências que dificulta ou impede que os viventes desse tempo compreendam, verdadeiramente, o que estão vivenciando e porque escolheram assim viver. Nesse sentido, os jargões: "seja você mesmo" ou "você pode ser aquilo que você quiser" nada mais fizeram do que dar aos frequentadores da contemporaneidade à ilusão de uma liberdade que, no fundo, proporciona o desenvolvimento de uma personalidade enfraquecida que culmina com um não conhecimento de si. Com essas bases, os diferentes processos educacionais, se perdem nos fracassos de seus pseudos êxitos. Novamente, precisamos nos sensibilizar para com essa realidade, pois ela reflete a vida dos contemporâneos. A filosofia não pode ignorá-la. O que cabe a ela então? Esperamos que as reflexões anteriores os ajudem...

A contemporaneidade é uma época onde muitas decisões são tomadas tendo como referência apenas especulações ou conceitos que emergiram de informações que se apresentam como neutras, mas que possuem interesses claros e sólidos. Interesses esses que, na maioria das vezes, são maquiados. É nesse lugar que a filosofia precisa agir, por isso nem sempre ela será bem-vinda, lembrem-se disso.

Diante desse cenário propomos que as experiências na e com a contemporaneidade sejam marcadas com novos sinais. Se for da vontade humana entender esse tempo e enfrentar os desafios que ele apresenta, então, as experiências humanas precisam ser repensadas. Eis o desafio, pois, se estar na contemporaneidade não necessariamente significa ser contemporâneo, logo, querer ser um sujeito de seu tempo implica em vivenciar experiências que possibilitem a efetivação desse querer. Isso pode significar sair da contemporaneidade e ou ir contra ela. Walter Benjamin sugere viver uma história a contrapelo, é quase como se fosse, caminhar na contramão.

Acreditamos na vivência dessas experiências e na fundamentação desse querer, por isso nos incluímos aos contemporâneos e não contemporâneos da contemporaneidade e propomos uma formação filosófica que nos permita fazer um recuo do presente para não seguirmos alheios ao nosso tempo. Sim, sabemos das exigências dessa postura, mas, por mais paradoxal que isso possa parecer, não nos parece que fugir dessa realidade seja a solução mais adequada. A filosofia como uma forma de vida poderá não ser a realidade de uma geração, mas se ela tiver esse desejo, mais do que abrir e alargar caminhos para quem está caminhando, deixará 
um caminho aberto para quem virá depois.

Para pensar: o lugar da filosofia na contemporaneidade é o que abriga experiências coletivas, e também não... O lugar da filosofia na contemporaneidade é o que abriga experiências que possibilitam seres humanos construírem-se como sujeitos de suas vidas, e também não...

\section{Referências bibliográficas}

HADOT, Pierre. La Filosofía como forma de Vida. Trad. María Cucurella Miquel. Barcelona: Alpha Decay, 2009.

AGAMBEN, Giorgio. O que é o contemporâneo? e outros ensaios. Chapecó, SC:

ARENDT, Hannah. A condição humana. 8. ed. Rio de Janeiro: Forense, 1997.

ARENDT, Hannah. Entre o passado e o futuro. Trad. Mauro Almeida. São Paulo: perspectiva, 2000.

BENJAMIN, Walter. Charles Baudelaire Um lírico no auge do capitalismo. Tradução Jose Carlos Martins Barbosa e Hemerson Alves Batista. 3.ed. São Paulo: Brasiliense. 1994b.

BENJAMIN, Walter. Magia e técnica, arte e política: ensaios sobre literatura e história da cultura. Tradução Sérgio Paulo Rouanet. 7.ed. São Paulo: Brasiliense. 1994a

BENJAMIN, Walter. Reflexões: a criança, o brinquedo, a educação. São Paulo: Sumus. 1984.

GAGNEBIN, Jeanne Marie. História e narração e Walter Benjamin. Fapesp, Campinas, São Paulo. 1994.

JAPIASSÚ, Hilton. MARCONDES, Danilo. Dicionário básico de filosofia. 5 ed. Rio de Janeiro: Jorge Zahar Ed., 2008.

NETO, Rodrigo Ribeiro Alves. O que significa ser contemporâneo?: Hannah Arendt e o tempo do pensamento. In: AGUIAR, Odilio Alves... [et al.] $\mathrm{O}$ futuro entre o passado e o presente: Anais do V encontro Hannah Arendt. Passo Fundo: IFIBE, 2012.

Contribuição dos autores:

Os autores Claudecir Dos Santos e Odair Neitzel participaram da discussão, problematização, revisão e redação do artigo. Todos os autores aprovaram a versão final do texto. 